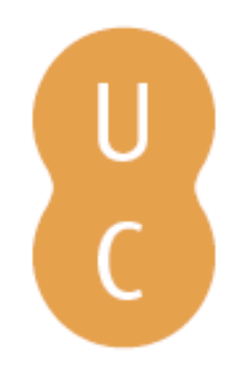

\title{
pommalina
}

\section{Em memória da grande tragédia ferroviária de Alcafache: a resposta da 1. linha}

Autor(es): $\quad$ Laranjeira, José; Almeida, Albano Ribeiro de; Borges, Américo Pais

Publicado por: Imprensa da Universidade de Coimbra

URL

persistente: URI:http://hdl.handle.net/10316.2/41817

DOI: $\quad$ DOl:https://doi.org/10.14195/978-989-26-1386-4_6

Accessed : $\quad$ 26-Apr-2023 13:07:28

A navegação consulta e descarregamento dos títulos inseridos nas Bibliotecas Digitais UC Digitalis, UC Pombalina e UC Impactum, pressupõem a aceitação plena e sem reservas dos Termos e Condições de Uso destas Bibliotecas Digitais, disponíveis em https://digitalis.uc.pt/pt-pt/termos.

Conforme exposto nos referidos Termos e Condições de Uso, o descarregamento de títulos de acesso restrito requer uma licença válida de autorização devendo o utilizador aceder ao(s) documento(s) a partir de um endereço de IP da instituição detentora da supramencionada licença.

Ao utilizador é apenas permitido o descarregamento para uso pessoal, pelo que o emprego do(s) título(s) descarregado(s) para outro fim, designadamente comercial, carece de autorização do respetivo autor ou editor da obra.

Na medida em que todas as obras da UC Digitalis se encontram protegidas pelo Código do Direito de Autor e Direitos Conexos e demais legislação aplicável, toda a cópia, parcial ou total, deste documento, nos casos em que é legalmente admitida, deverá conter ou fazer-se acompanhar por este aviso. 
IMPRENSA DA UNIVERSIDADE DE COIMBRA

COIMBRA

UNIVERSITY

PRESS
LUCIANO LOURENÇO (COORD.)

ALCAFACHE

30 ANOS DEPOIS

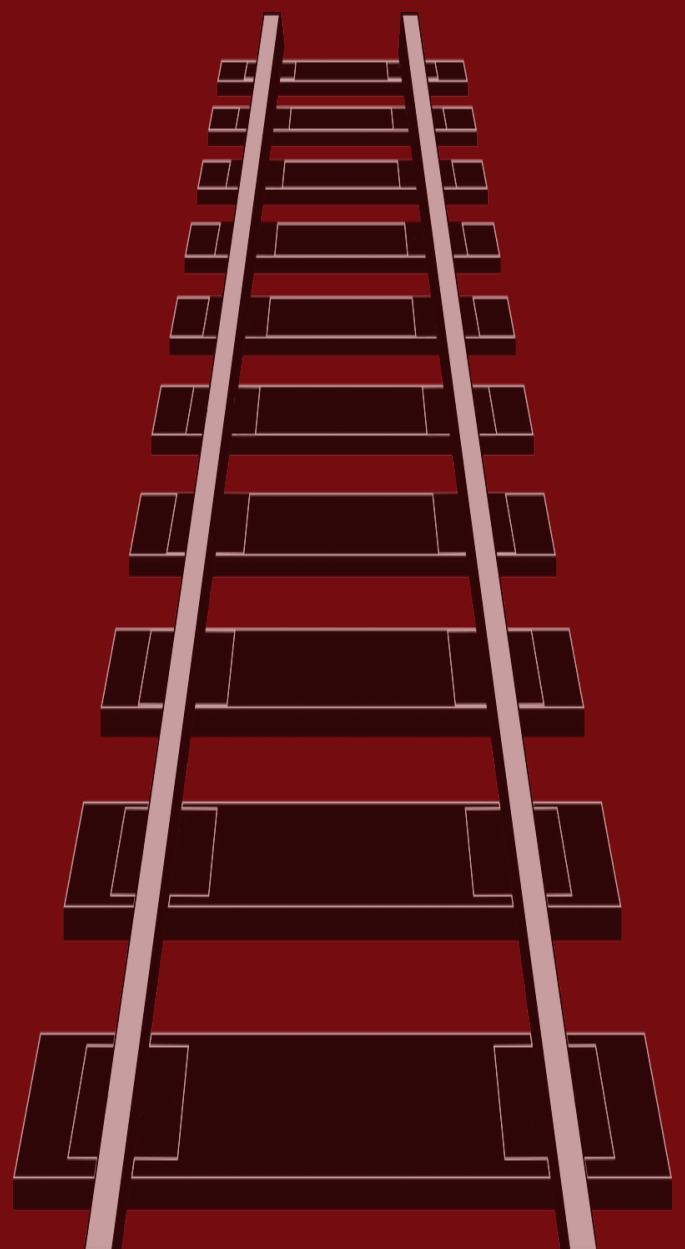




\section{EM MEMÓRIA DA GRANDE TRAGÉdIA FERROVIÁRIA DE ALCAFACHE. A RESPOSTA DA 1. a LINHA \\ IN MEMORY OF THE BIG RAILWAY TRAGEDY OF ALCAFACHE. THE $1^{\text {ST }}$ LINE RESPONSE}

\section{José Laranjeira \\ Ex -residente da Direcçáo do Serviço Nacional de Bombeiros}

\section{Albano Ribeiro de Almeida \\ Ex-Inspetor Regional de Bombeiros do Centro do Serviço Nacional de Bombeiros \\ Américo Pais Borges \\ Ex-Comandante do Corpo de Bombeiros Voluntários de Canas de Senhorim}

Sumário: Apesar de terem decorrido 30 anos sobre o acidente ferroviário de Alcafache, ele ainda está bem presente na memória de quem o viveu e, muito em particular, daqueles que na altura detinham responsabilidades diretas no socorro às vítimas. A descriçáo do modo como foi prestada essa assistência, narrada pelos três responsáveis do então Serviço Nacional de Bombeiros, respetivamente a nível local, regional e nacional, ajuda a situar-nos no contexto da época e das condiçôes em que foi prestado o socorro. Além da descriçáo do sucedido, com o envolvimento de diferentes agentes de proteção civil, em função da fita do tempo, apresentam-se também algumas das consequências que este acidente determinou, quer para a melhoria das condiçóes de segurança nas vias férreas, quer para o conhecimento da Medicina de Catástrofe.

Palavras-chave: Emoção, stress no trabalho, trauma, emergência, ferrovia. 
Abstract: Although 30 years have passed on the Alcafache railroad accident, it is still very much in the memory of those who lived there and, in particular, of those who at the time had direct responsibilities in helping the victims. The description of the manner in which this assistance was provided, narrated by the three heads of the then National Fire Service, at local, regional and national level, helps situating ourselves in the context of the time and conditions under which help was provided. In addition to the description of what happened, with the involvement of different civil protection agents, as a function of the time tape, some of the consequences that this accident has determined, both for the improvement of the safety conditions on the railroads and for the knowledge of Catastrophe Medicine

Keywords: Emotions, job stress, trauma, workers, railway.

\section{Introdução}

No dia 11 Setembro de 1985, o Presidente da Direção do Serviço Nacional de Bombeiros, Eng. ${ }^{\circ}$ José António da Piedade Laranjeira andava na Região Centro, a recolher elementos sobre o resultado das medidas que o Serviço Nacional de Bombeiros (SNB), estava gradualmente a implantar no combate aos Fogos Florestais.

Com efeito, esse ano fora bastante complicado do ponto de vista do combate, dadas as condiçôes meteorológicas adversas, pois esse verão foi extramente quente, com vários dias em que a temperatura ultrapassou 30 graus Celsius e a humidade relativa do ar foi inferior a 30\%, valores favoráveis à progressão dos incêndios florestais. No entanto, dias antes, mais precisamente a 8 de setembro, vários Corpos de Bombeiros que se encontravam a combater um incêndio florestal no Carvalhal da Mulher, na serra do Caramulo, foram surpreendidos por uma trovoada que desabou sobre essa região e ajudou a extinguir os incêndios florestais, designadamente o que matou 16 bombeiros em Armamar. 
Essa viagem decorria algures, na Estrada da Beira, e quando se preparava para comer algo, foi alertado para o facto de ter sido detetado mais um incêndio perto de Nelas, uma situação que, embora sendo normal para a época, sempre preocupava pelo facto de serem incêndios a mais num país tão pequeno.

Entretanto, o Comandante dos Bombeiros Voluntários de Canas de Senhorim, Dr. Américo Pais Borges, que pelas 18H35 desse fático dia 11 de Setembro de 1985, se encontrava na Central Rádio dos seus Bombeiros Voluntários, ouviu uma mensagem transmitida por uma ambulância do Corpo de Bombeiros Voluntários de Aguiar da Beira, solicitando o envio de ambulâncias para a estrada de Nelas-Mangualde. De imediato mandou sair as 4 ambulâncias de que a Corporação dispunha na altura, com as respetivas tripulaçóes, enquanto pedia às Corporaçóes mais próximas que também enviassem as ambulâncias disponíveis para o local, mesmo sem saber de que tipo de acidente se tratava, pois quando, naturalmente, os bombeiros the perguntavam o que se passava, a sua reposta era "não sei, possivelmente será um acidente, ou um choque de cadeia de viaturas, ou um autocarro que teve um acidente".

O Comandante Américo Pais Borges tentou inquirir o tripulante da ambulância de Aguiar da Beira perguntando-lhe a localização exata do acidente e o que efetivamente se estava a passar, mas não obteve reposta. $\mathrm{O}$ bombeiro continuava insistentemente a pedir ambulâncias para a estrada Nelas-Mangualde e, naquilo que the pareceu ser muito tempo, mas provavelmente foram uns escassos minutos, o tripulante da ambulância de Aguiar da Beira lançou novo apelo, em que solicitava o envio de "Autotanques pois as Carruagens estavam a arder". Nessa altura, apercebeu-se de que se tratava de um acidente ferroviário e fez o alerta geral às Corporaçóes de Bombeiros, assumindo assim, desde o início, o comando e o controlo do sinistro.

\section{$\mathrm{O}$ acidente ferroviário de Alcafache}

$\mathrm{O}$ acidente ocorreu na linha férrea da Beira-Alta, que era e continua a ser de via única, na altura ainda não estava eletrificada, mas possuía trânsito intenso, 
pois era a principal via de acesso para a Europa. Os dois comboios envolvidos no desastre, o Sud-Expresso com destino à Europa e um comboio regional, transportariam cerca de 350 passageiros. No primeiro deles viajavam muitos emigrantes, que regressavam aos seus países de acolhimento, acompanhados por elevadas quantidades de produtos regionais, que ficaram muito danificados e até misturados com corpos carbonizados.

As ambulâncias enviadas pelo Corpo de Bombeiros de Canas de Senhorim chegaram ao local, cerca de 5 minutos após o acidente, logo seguidas pelas dos Bombeiros de Nelas e de outras Corporaçôes, tendo começado a evacuar os feridos para o Hospital de Viseu e para os Centros de Saúde de Nelas e de Mangualde.

Logo que o Comandante Pais Borges tomou conhecimento do tipo de acidente, fez sair de imediato um Autotanque, equipado com material de desencarceramento e espumífero, no qual também se deslocou para o local.

A cerca de dois quilómetros, do local do acidente logo avistaram uma enorme coluna de fumo negro que, efetivamente, indiciava carruagens incendiadas. Ao chegarem ao local, felizmente próximo da Estrada Nacional 234, que une os concelhos de Mangualde e Nelas, com a linha férrea a distar menos 50 metros da estrada nacional, depararam-se com uma visão caótica (fot. 1): "carruagens a arder do Sud-Expresso, carruagens a arder do comboio regional, carruagens descarriladas, carruagens na linha, locomotivas quase desaparecidas".

Autotanque do CB de Canas de Senhorim, em que seguia o Comandante Américo Pais Borges e alguns operacionais, chegou ao local pelas $18 \mathrm{H} 50$ e imediatamente eles secundaram os bombeiros no combate ao incêndio que devorava as carruagens do Sud-Expresso e também uma do Comboio Regional, mas só foi possível atenuar e, depois, extinguir o incêndio, com recurso a espuma, pois os materiais que ardiam eram fundamentalmente plásticos, cabedal e napas, além de que exalavam fumos muito densos (fot. 1 e 2), que impediam os bombeiros de penetrarem no interior das carruagens, mesmo com máscaras de circuito fechado.

Só constataram isso após uma atitude de alguma imprevidência, que os levou a penetrar no interior de uma carruagem e que, apesar da agulheta de alta pressão que transportavam, teriam lá ficado, não fora um bombeiro tê-los arrastado para o exterior. 
Entretanto, iam tentando entrar nas carruagens. Todas elas eram carruagens-cama com 10 compartimentos. A segunda carruagem do Sud-Expresso, que não tinha ainda ardido, estava descarrilada e tinha apenas 6 compartimento, pois os primeiros 4 , devido ao choque, tinham funcionado como um harmónio e não estavam lá. No primeiro dos outros compartimentos, que seria o quinto, encontraram uma senhora encarcerada pela cama que, após duas horas de trabalho exaustivo de desencarceramento, foi extraída viva e sem danos aparentes,

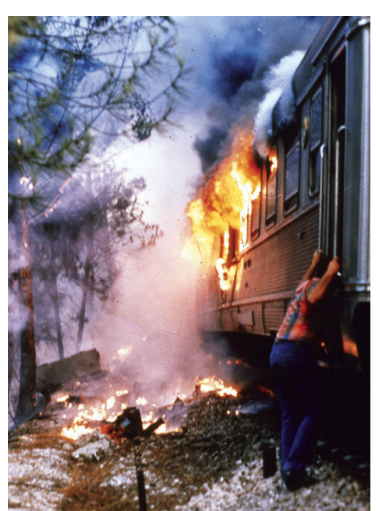

A

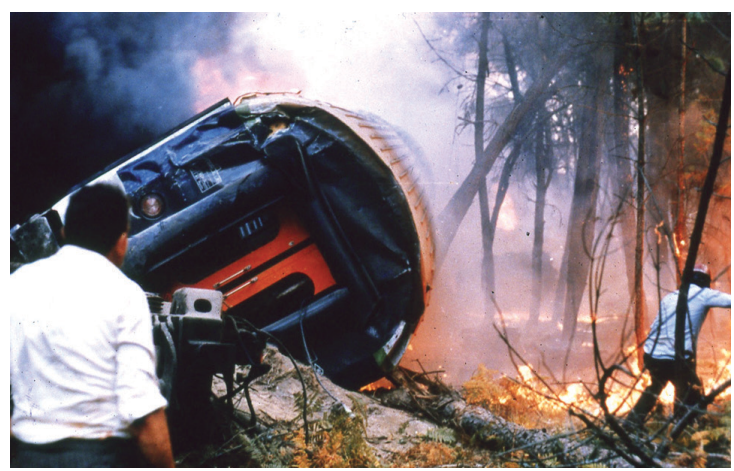

C

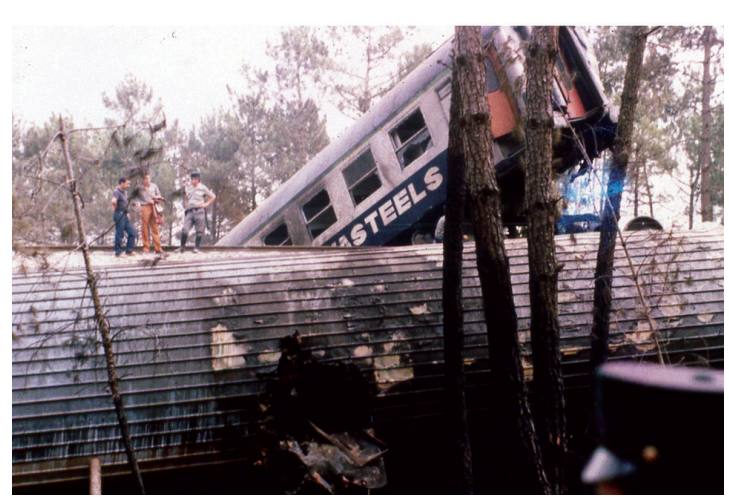

B

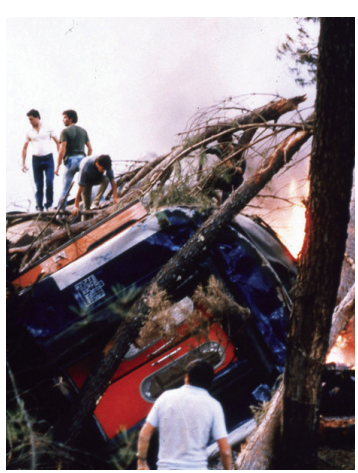

D

Fot. 1 - Imagens do Acidente: a) Pormenor de uma carruagem a arder; b) Posição em que ficaram duas carruagens; c) Detalhe de uma carruagem sinistrada e propagaçáo do incêndio à floresta; d) Material circulante danificado (Fotografias de A. Ribeiro de Almeida).

Photo. 1 - Images of the Accident: a) Detail of a carriage burning; b) Position in which two carriages stayed; c) Detail of a sinister carriage and fire spread to the forest d) Damaged rolling stock (Photographs by A. Ribeiro de Almeida). 


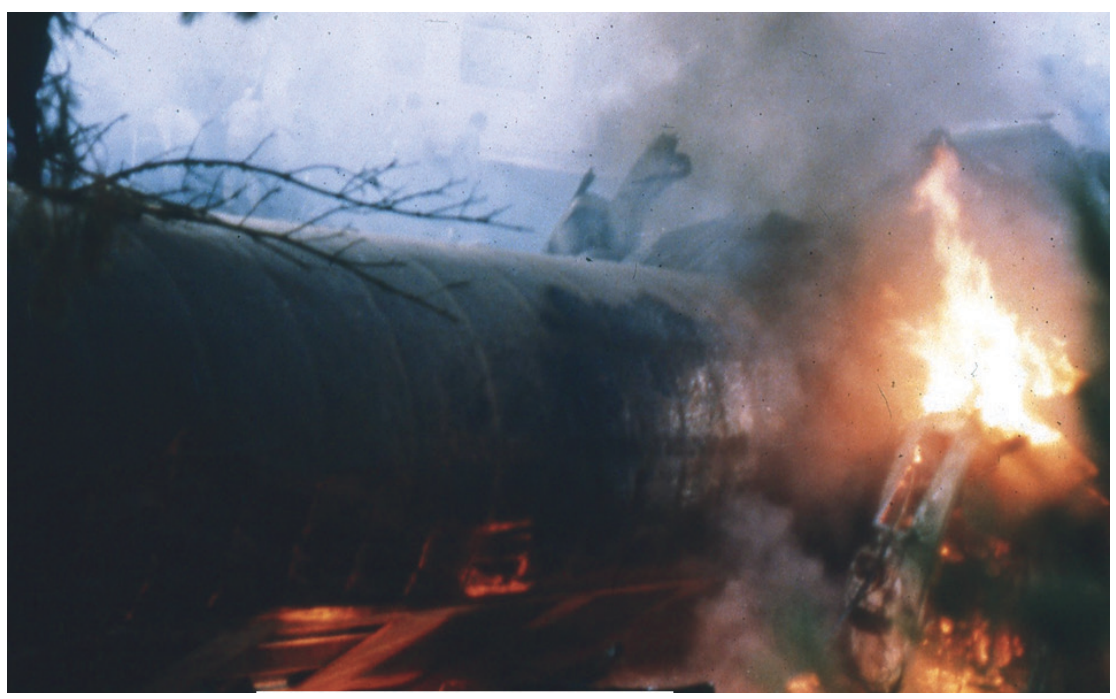

A

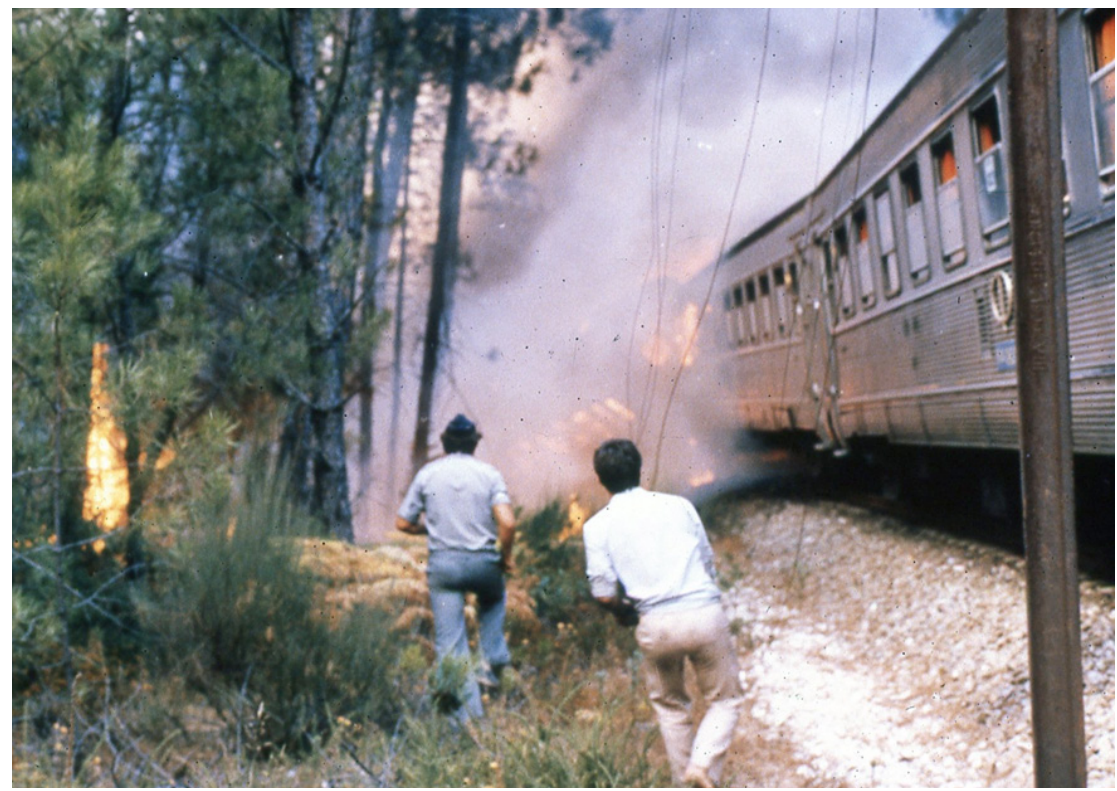

B

Fot. 2 - Carruagens a arder: a) Detalhe de uma das carruagens sinistradas a ser consumida pelo fogo; b) Pessoal em socorro (Fotografias de A. Ribeiro de Almeida).

Photo. - Carriages burning: a) Detail of one of the carriages being consumed by the fire; b) Personnel in distress (Photographs by A. Ribeiro de Almeida). 
pela janela do lado esquerdo, visto que a carruagem estava tombada sobre o lado esquerdo, em relaçáo a quem está voltado para a fronteira.

Depois, começaram a entrar em mais carruagens, onde era possível fazê-lo, na tentativa de encontrar ainda alguém com vida (fot. 3). No entanto, eram só cadáveres ... "digo-vos que não é fácil, 30 anos depois, lembrar-me daquilo que vi..."

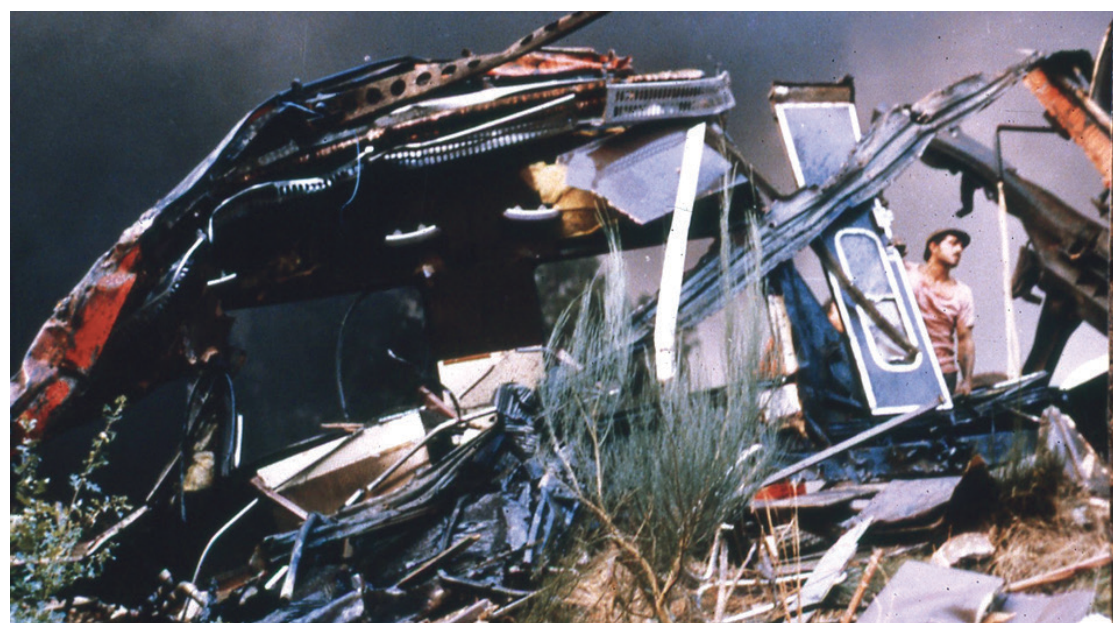

A

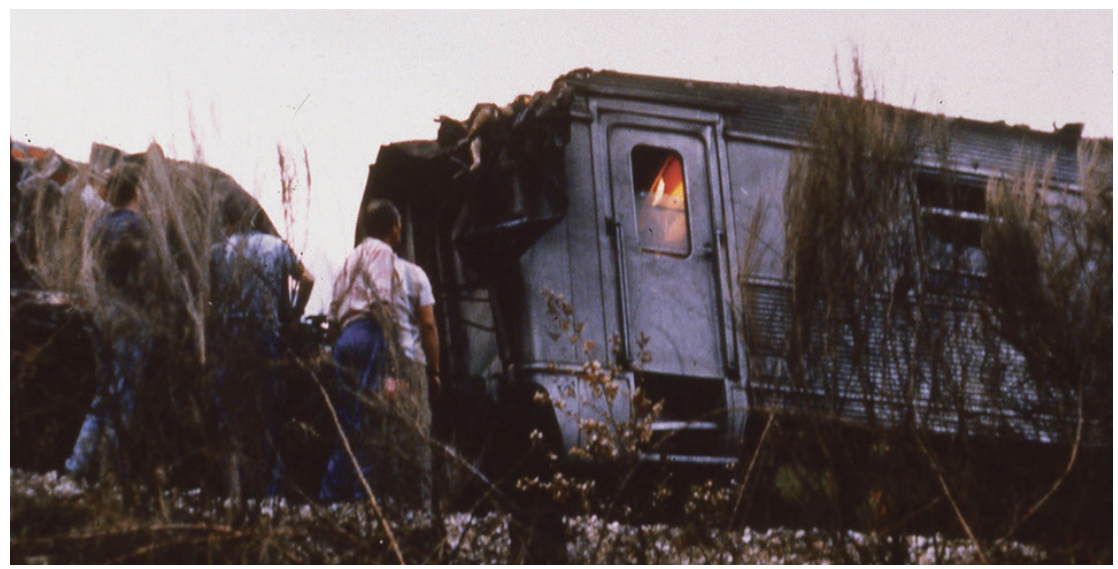

B

Fot. 3 - Aspetos do acidente: a) Material circulante destruído; b) Pessoal em socorro (Fotografias de A. Ribeiro de Almeida).

Photo. 3 - Aspects of the accident: a) Rolling stock destroyed; b) Personnel in distress (Photographs by A. Ribeiro de Almeida). 
Entretanto, foi solicitado às forças da Guarda Nacional Republicana presentes no local para que afastassem os inúmeros civis que ali se encontravam, trabalho que foi executado de maneira eficiente, como só a GNR sabe fazer, permitindo que as vias de socorro ficassem desimpedidas e, assim, se facilitasse a deslocação dos homens e dos meios de prestação de socorro. A GNR, teve um papel extraordinário na regularização do trânsito na EN 234, junto ao local do acidente, permitindo a chegada e saída dos meios de socorro, sem problemas.

Por outro lado, foi solicitado à Pista de Viseu que fizesse uma alerta geral, no sentido de fazer deslocar para o local mais Corpos de Bombeiros portadores de material de iluminação, visto que a área não era iluminada. O Comandante de Pista era o Comandante Alexandre, dos Bombeiros Voluntários de Lagares da Beira, que foi um grande auxiliar, de uma competência extraordinária no envio de meios de socorro. Também foi pedido à Pista de Viseu para combater com meios aéreos o incêndio que ali também ocorria, e que estava a agravar fortemente a situaçáo, pois fora provocado pelo acidente e acelerado pelo combustível derramado no embate frontal das duas locomotivas e que se tinha propagado à mata contígua à via-férrea. Este pedido foi satisfeito de imediato e os avióes canadair fizeram descargas sobre o comboio e o pinhal circundante.

O cenário era dantesco: carruagens descarriladas, corpos amalgamados juntamente com corpos carbonizados, carruagens a arder, a temperatura nalgumas carruagens em chamas era tão elevada que derreteu alumínio, cujo ponto de fusão é de $660,3^{\circ} \mathrm{C}$, o que permite avaliar as temperaturas que então se desenvolveram e que deram origem a focos de incêndios na mata circundante (fot. 4).

Seguiu-se a repetição da vistoria às carruagens, principalmente do SudExpresso, mas também às do comboio regional, no sentido de encontrar sobreviventes que, porventura, tivessem escapado à primeira vistoria efetuada pelos primeiros bombeiros chegados ao local, mas não foi encontrado mais ninguém vivo. Todas as operaçôes se desenrolaram sem atropelos, pois cada bombeiro sabia qual era a sua missão e efetuava-a impecavelmente.

Fora do Teatro das Operações, o Presidente da Direção do Serviço Nacional de Bombeiros e o Inspetor Regional de Bombeiros do Centro tomaram conhecimento do acidente, pela escuta rádio permanente da Central de Rádio da 
Inspeção Regional de Bombeiros da Região Centro, em Coimbra, bem como pela informação proveniente da Pista de Viseu, em funcionamento naquela altura, por ainda ser "época de incêndios florestais", a qual dispunha tanto de avióes

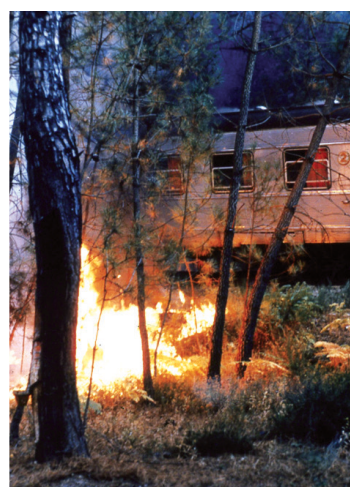

A

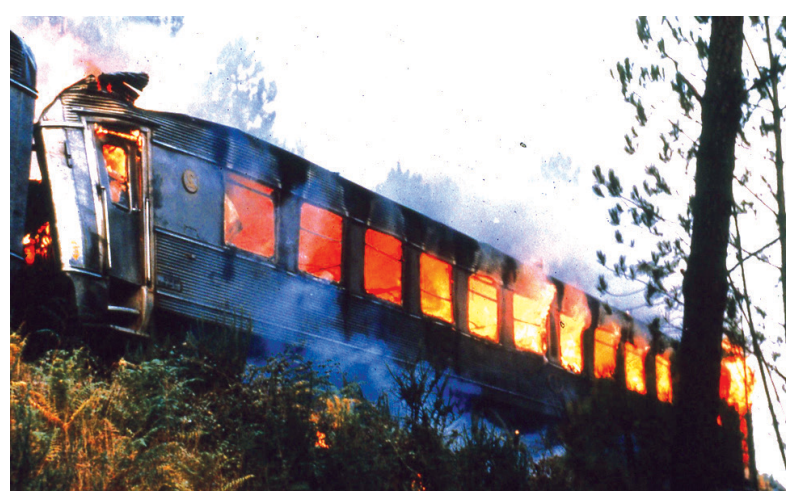

C

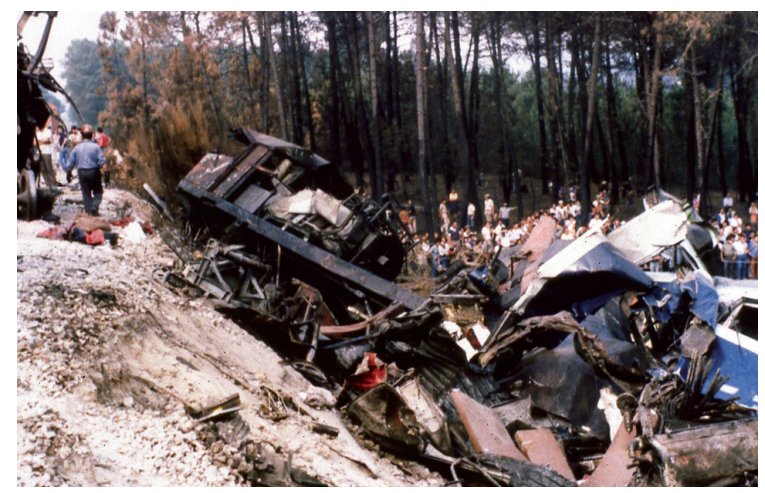

B

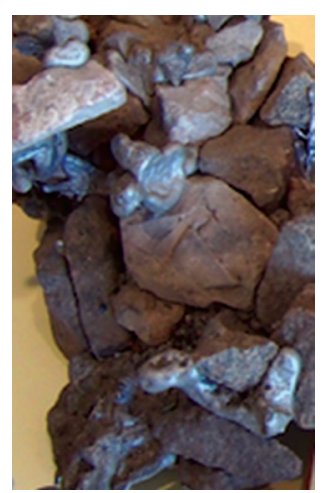

$\mathrm{D}$

Fot. 4 - Carruagens a arder e propagação do incêndio à floresta envolvente: a) Pormenor da propagação do fogo duma carruagem para a vegetação circundante; b) Restos de carruagem destruída e pormenor do pinhal queimado; c) Vista geral duma carruagem em chamas, da qual se libertou alumínio derretido que pegou fogo à vegetaçáo; d) Pormenor do alumínio derretido que solidificou nas pedras da brita da via férrea, recolhidas e religiosamente guardadas pelo Comandante Pais Borges (Fotogra-

fias de A. Ribeiro de Almeida (a, b, c) e de Sofia Bernardino (d)).

Photo. 4 - Carriages burning and propagating the fire to the surrounding forest: a) Detail of the spread of the fire of a carriage to the surrounding vegetation; b) Remains of carriages destroyed and details of the burned pine forest; c) Overview of a burning carriage, from which the molten aluminum was released and that set fire to the vegetation; $d$ ) Detail of the molten aluminum that solidified on the stones of the gravel of the railroad,

collected and religiously guarded by the Commander Pais Borges

(Photographs by A. Ribeiro de Almeida $(a, b, c)$ and Sofia Bernardino (d)). 
de combate a incêndios florestais, como de helicópteros para esse combate e para o transporte das brigadas helitransportadas. Em funçáo da gravidade da ocorrência, logo decidiram dirigir-se para o local do acidente.

Nos contactos rádio que foram estabelecendo, quer com a pista, quer com os CB da área, foram também conhecendo a evolução da situação. Sabiam que o acidente ocorrera na área de Coordenaçáo Operacional dos Bombeiros de Canas de Senhorim e que no local se encontrava o respetivo comandante, Dr. Pais Borges, o qual acionava e coordenava os meios. De igual modo, tiveram conhecimento do seu pedido à Pista de Viseu, para combater com meios aéreos o incêndio que ali também ocorria e que estava a agravar fortemente a situação, pois fora provocado pelo acidente e acelerado pelo combustível derramado no embate frontal das duas locomotivas. Entre outros contactos que estes dirigentes conseguiram estabelecer, destaca-se o efetuado com o entâo Delegado Distrital da Proteção Civil de Viseu, na altura Major Riquito, o qual informou sobre as suas diligências para socorro aos feridos e apoio aos sinistrados, as quais foram consideradas perfeitas por estes dirigentes.

Convém recordar que tanto os meios de coordenação operacional, como as comunicaçôes, comparativamente com a atualidade, eram ainda muito deficientes, pois náo havia instalados nem comandos operacionais, nem centros de coordenação distrital, que viriam a ser estruturas adequadas a situaçóes semelhantes, as quais estavam ainda numa fase embrionária, mas como as viaturas de comando já dispunham de emissóes rádio em banda alta, lá se ia conseguindo comunicar, embora não plenamente.

Quando chegaram ao local, ainda com restos do pôr-do-sol, depararam-se com uma situação de difícil descriçãoo (fot. 5). As equipas de socorro, basicamente constituídas por bombeiros, envoltas por pequenos focos de incêndio que se iam manifestando, procuravam socorrer as vítimas, em particular as que estavam ainda retidas dentro das composiçóes. O ambiente era devastador e muito difícil de aguentar sem virem as lágrimas aos olhos perante as inúmeras dificuldades em chegar a todos os lados onde vidas corriam perigo. Entretanto, chegou a noite mas, como tinham sido instalado projetores, foi possível continuar a trabalhar com alguma segurança. No entanto, tudo parecia irreal, fantasmagórico. 


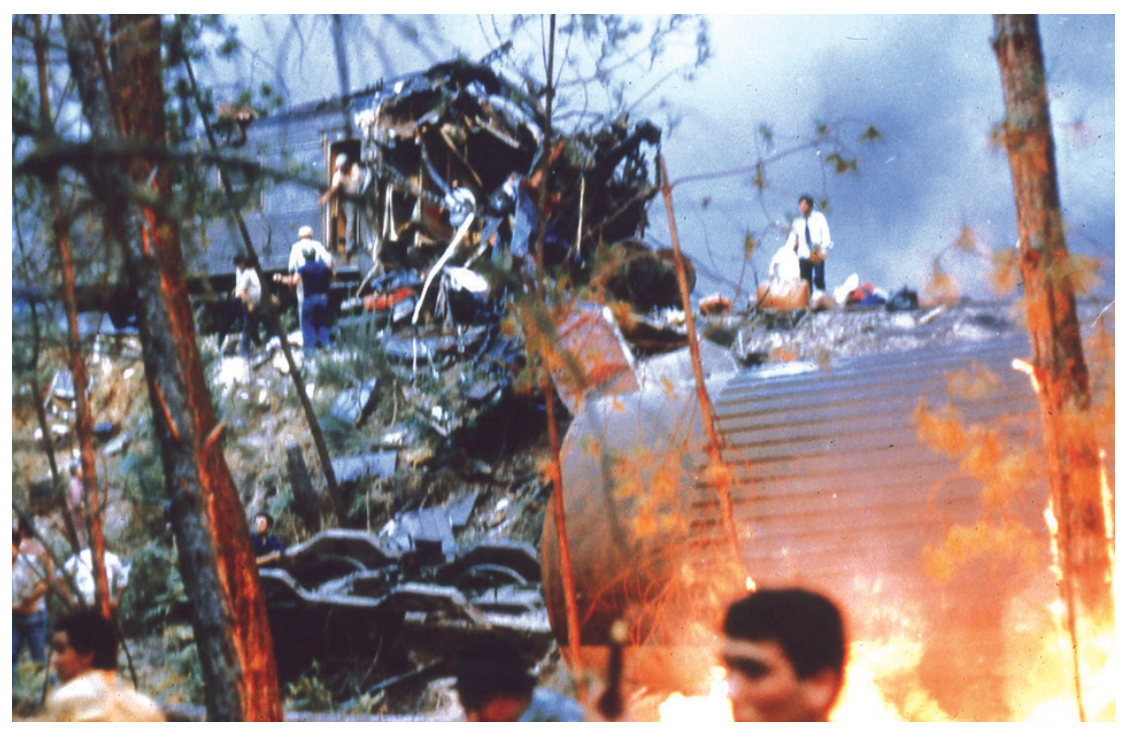

A

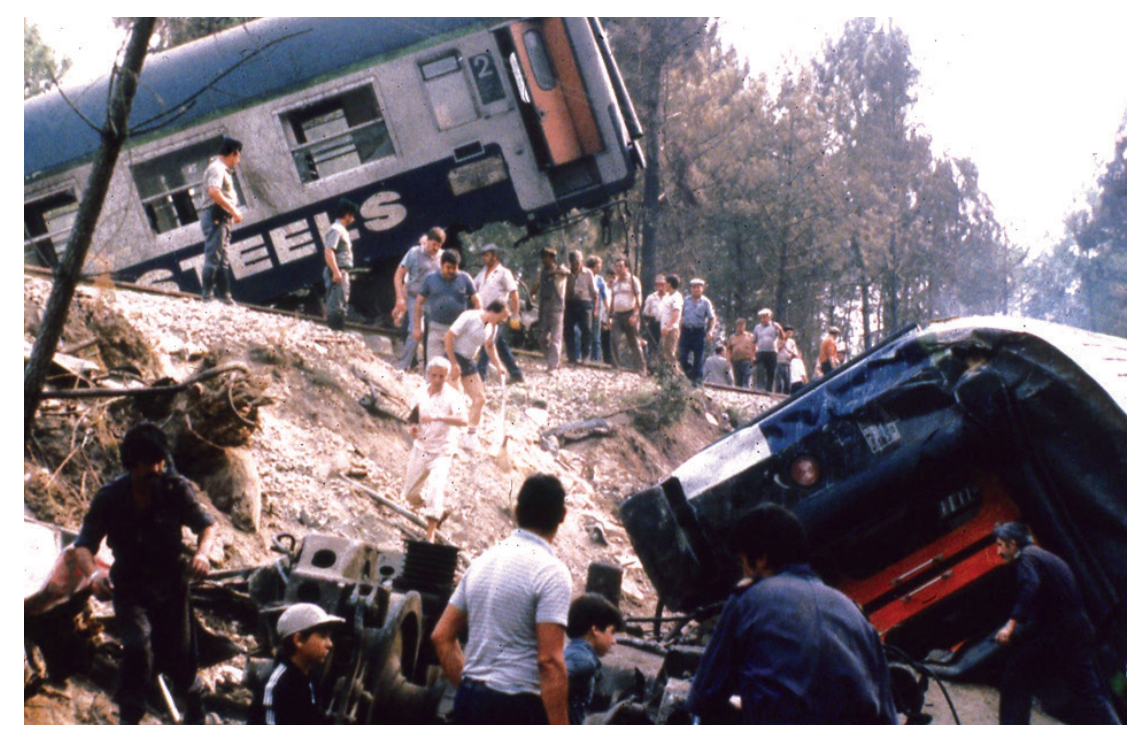

$\mathrm{B}$

Fot. 5 - Imagens da tragédia: a) Material circulante destruído e incêndio na floresta envolvente; b) Aspeto da dimensão do desastre

(Fotografias de A. Ribeiro de Almeida).

Photo. 5 - Images of the tragedy: a) Rolling stock destroyed and fire in the surrounding forest; b) Aspect of the dimension of the disaster

(Photographs by A. Ribeiro de Almeida). 
Restava-lhes a missão de mobilizar quem pudesse ajudar e animar quem estava ali em missão de socorro, para não se deixarem abater perante as dificuldades vividas e que eram muitas e de grande impacto emocional.

Cerca das $19 \mathrm{~h} 30$ compareceu no local o Sr. Governador Civil do Distrito de Viseu, acompanhado pelo Capitão Aguiar que era membro do Serviço Distrital de Proteção Civil, a quem foi efetuado o pedido de autorização para procurar alojamento para os sobreviventes não feridos, pedido esse que foi aceite.

Entretanto, iam chegando ao local mais individualidades políticas, existentes na época, designadamente o Sr. Ministro da Administração Interna, Eng. ${ }^{\circ}$ Eduardo Pereira, que foi o primeiro elemento do Governo a chegar ao local e a acompanhar de perto os trabalhos de socorro que, com o avançar da noite, se tornavam cada vez mais difíceis e problemáticos. Depois, compareceram também os senhores: Secretário de Estado das Comunicaçôes, Dr. Raul Junqueiro; Presidente da República, General Ramalho Eanes; Primeiro-Ministro, Dr. Mário Soares; Ministro da Saúde e, outros membros do Governo. Todos eles foram unânimes em elogiar o trabalho dos bombeiros.

Um acidente com estas dimensóes não deixou de mobilizar outros agentes da Proteção Civil, como foi o caso da Cruz Vermelha e da Guarda Nacional Republicana, e, ainda, de um outro agente, nem sempre referido, que diz respeito aos cidadáos das comunidades vizinhas que ocorreram e colaboraram nos trabalhos em curso.

De louvar a solidariedade das populaçóes de Mangualde e de Nelas, dos jornalistas da RPT e das rádios e dos jornais, de empresas que na época comercializavam sumos, leite, sandes, pois foram inexcedíveis em levar aos socorristas do acidente de Alcafache tudo aquilo de que precisavam e até do que não careciam.

A prestação do socorro funcionou bem (fot. 6), acima de tudo graças à competência tanto das brigadas de trânsito da GNR, como dos bombeiros, primeiro de Canas de Senhorim e depois das corporaçóes limítrofes, que conseguiram transportar sem qualquer perda de tempo os sinistrados de Alcafache ao Hospital Distrital de Viseu e aos Centros de Saúde de Mangualde e de Nelas, porque este ficava mais perto do acidente do que o de Mangualde. O IP5 já se encontrava construído entre Mangualde e Viseu, mas não estava aberto ao 
público, tendo sido inaugurado pelas ambulâncias dos bombeiros. Cortou-se o trânsito na estrada N234 entre o local do acidente e Mangualde. Os Centros de Saúde de Nelas e de Mangualde, bem como o Hospital de Viseu, respondiam da melhor maneira. Os dadores de sangue surgiam e a tradicional hospitalidade beirã funcionou uma vez mais, com as populações de Mangualde e Nelas a prestarem apoio aos passageiros dos comboios e aos seus bombeiros.

Nos dois dias imediatos, os Bombeiros de Canas de Senhorim, Mangualde e Nelas mantiveram-se no teatro das operaçôes para colaborarem na remoção das carruagens e na desinfeção do local.

A televisão e a rádio fizeram a cobertura noticiosa do sinistro com reportagens, entrevistas e com a preocupação de saber o número de sinistrados e de mortos. Todavia, esse número não se conseguiu apurar, como também não sabemos o dos desaparecidos, ou mesmo se os houve. A RTP produziu uma reportagem nessa noite, em direto, a qual correu em ecrãs de muitos países do mundo.

O número de mortos de Alcafache, não foram 200 como dizia uma edição especial do Comércio do Porto, nem foram os 57 que, na altura, o Comandante Pais Borges adiantou para a comunicaçáo social e que contou, por excesso, em

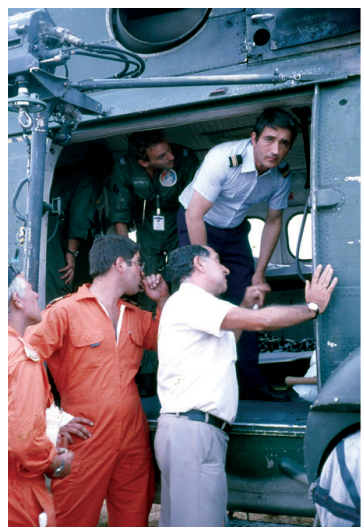

A

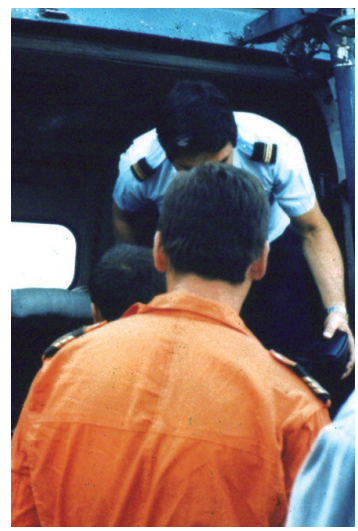

B

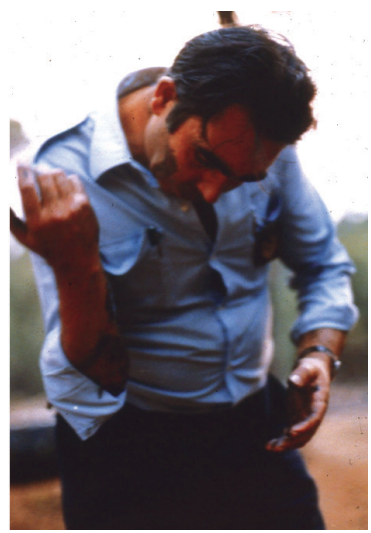

C

Fot. 6 - Aspetos do socorro aos feridos: a) Transporte de feridos em helicóptero; b) Embarque de feridos; c) Pessoal de socorro (Fotografias de A. Ribeiro de Almeida).

Photo. 6 - Aspects of the help to the wounded: a) Transportation of wounded by helicopter; b) Embarkation of wounded persons; c) Help personnel (Photographs by A. Ribeiro de Almeida). 
funçáo dos corpos retirados das carruagens. Passados 30 anos, ele continua convicto de que não terão chegado a 150 , e, com certeza, não foram os 200 mencionados no jornal, mas teráo sido mais do que os 57 que, na altura, referiu.

Nos dias de hoje, todos nós acompanhamos as tragédias que ocorrem no país e, nestes casos, o INEM envia psicólogos, no sentido de minorar os traumas sentidos, não só pelos familiares das vítimas mas também pelos socorristas que desempenham as suas funçôes. Em Alcafache os bombeiros também tiveram apoio psicológico, embora diferente do atual, traduzido nos ombros uns dos outros e nas lágrimas que choraram quando removiam os corpos carbonizados, imagens que nunca mais esqueceram.

Como ficou conhecido, Alcafache serviu para demonstrar que os Bombeiros de Portugal são competentes, sabem socorrer muito bem e são o sossego para uma vida segura. Serviu ainda para criar sentimentos de prevenção, concretamente nos comboios, os quais teriam evitado o acidente, se existissem na época.

\section{Conclusão}

Esta catástrofe marcou a transição do socorro em acidentes ferroviários do antes para o depois de Alcafache, com o aprofundamento, estudo e implementaçáo de técnicas, tanto de prevenção, como de socorro. Foi, sobretudo, graças ao acidente de Alcafache que se criaram condiçôes para sensibilizar as Faculdades de Medicina para a necessidade de criar conhecimento em Medicina de Catástrofe.

Um acidente, seja qual for a sua dimensão, tem, à partida, vítimas ou prejuízos materiais, e a função do socorro é minorar esses efeitos negativos. Neste caso, dois fatores influenciaram a prontidão do socorro e a sua atuação:

a) O sistema, entáo montado, para o Combate aos Fogos Florestais, traduzido designadamente na deteção do foco de incêndio originado pelo acidente, bem como na intervenção dos meios aéreos sediados no aeródromo de Viseu, e, ainda, na recém criada estrutura de Comandos 
Operacionais e de Brigadas de Primeira Intervenção, ao tempo em curso de implementaçáo e desenvolvimento.

b) O local do acidente, por este ter tido lugar numa zona plana e ter sido próximo de uma estrada nacional, o que permitiu uma grande facilidade de acesso ao socorro. Com outra tipologia do local do acidente, ou seja, de mais difícil acesso, as consequências deste acidente teriam sido bem mais graves.

Poderáo passar muitos anos, do mesmo modo que muitos dos pormenores vividos naquela situação poderão desaparecer da memória dos intervenientes, mas quem viveu aquele panorama de gente aflita não mais esquecerá como nos sentimos impotentes para enfrentar táo dura realidade, na qual dezenas de nossos concidadãos perderam a vida.

O passar dos anos vai ensinado que, quando a vida dos outros corre perigo, mais se fortalece o princípio de que o socorro tem como pedra basilar a PREVENÇÃO, pelo que quanto mais cuidados se desenvolverem e mais se respeitarem, menores seráo os RISCOS e mais eficiente será o SOCORRO.

Esta é a história do acidente de Alcafache e da saga heroica dos bombeiros que intervieram nesse acidente ferroviário. A propósito da atuação dos bombeiros, se Luís Vaz de Camóes tivesse estado em Alcafache, teria repetido a frase "bendita pátria que tais filhos tem"!

\section{Bibliografia}

Laranjeira, José António da Piedade (2016). Alcafache - a grande catástrofe ferroviária. Livro de resumos do X Encontro Nacional de Riscos e II Jornadas Técnicas da Federação de Bombeiros do Distrito de Viseu, RISCOS, Viseu.

Pais Borges, Américo (2016). A resposta da 1. a linha (Relatório do Acidente Ferroviário de Alcafache). Livro de resumos do X Encontro Nacional de Riscos e II Jornadas Técnicas da Federação de Bombeiros do Distrito de Viseu, RISCOS, Viseu.

Ribeiro de Almeida, Albano José (2016). Em memória do desastre de Alcafache. Livro de resumos do X Encontro Nacional de Riscos e II Jornadas Técnicas da Federação de Bombeiros do Distrito de Viseu, RISCOS, Viseu. 